\title{
Beyond Axon Guidance: Roles of Slit-Robo Signaling in Neocortical Formation
}

\author{
Yuko Gonda ${ }^{1 *}$, Takashi Namba ${ }^{2,3}$ and Carina Hanashima ${ }^{4,5}$ \\ ${ }^{1}$ Department of Histology and Neuroanatomy, Tokyo Medical University, Tokyo, Japan, ${ }^{2}$ Max Planck Institute of Molecular \\ Cell Biology and Genetics, Dresden, Germany, ${ }^{3}$ Neuroscience Center, HiLIFE - Helsinki Institute of Life Science, University \\ of Helsinki, Helsinki, Finland, ${ }^{4}$ Faculty of Education and Integrated Arts and Sciences, Waseda University, Tokyo, Japan, \\ ${ }^{5}$ Graduate School of Advanced Science and Engineering, Waseda University, Tokyo, Japan
}

OPEN ACCESS

Edited by:

Yuki Hirota,

Keio University, Japan

Reviewed by:

David Lutz,

Ruhr-University Bochum, Germany

Tatsumi Hirata,

National Institute of Genetics, Japan

${ }^{*}$ Correspondence:

Yuko Gonda

gonda@tokyo-med.ac.jp

Specialty section:

This article was submitted to

Cell Adhesion and Migration,

a section of the journal

Frontiers in Cell and Developmental

Biology

Received: 17 September 2020 Accepted: 07 December 2020

Published: 23 December 2020

Citation:

Gonda $Y$, Namba T and Hanashima C (2020) Beyond Axon Guidance: Roles of Slit-Robo

Signaling in Neocortical Formation. Front. Cell Dev. Biol. 8:607415. doi: $10.3389 /$ fcell.2020.607415
The formation of the neocortex relies on intracellular and extracellular signaling molecules that are involved in the sequential steps of corticogenesis, ranging from the proliferation and differentiation of neural progenitor cells to the migration and dendrite formation of neocortical neurons. Abnormalities in these steps lead to disruption of the cortical structure and circuit, and underly various neurodevelopmental diseases, including dyslexia and autism spectrum disorder (ASD). In this review, we focus on the axon guidance signaling Slit-Robo, and address the multifaceted roles of Slit-Robo signaling in neocortical development. Recent studies have clarified the roles of SlitRobo signaling not only in axon guidance but also in progenitor cell proliferation and migration, and the maturation of neocortical neurons. We further discuss the etiology of neurodevelopmental diseases, which are caused by defects in Slit-Robo signaling during neocortical formation.

Keywords: Robo, Slit, neocortex, migration, proliferation, dendrite, spine, axon guidance

\section{INTRODUCTION}

The neocortex is the six-layered outermost structure of the cerebrum, and is considered to be an evolutionarily new region of the brain that appeared soon after the emergence of mammals. Humans have the largest neocortex relative to their body size, which is thought to underlie their higher brain functions, such as cognition and emotion (Rakic, 2009).

The neocortex consists of two main types of neurons, i.e., excitatory projection neurons and inhibitory interneurons, which are generated from distinct germinal zones in the developing cerebrum, corresponding to the dorsal and ventral telencephalon, respectively. In both regions, the germinal zones are divided into two territories. The first is the ventricular zone (VZ), which lines the ventricles and occupies the apical-most region of the cerebral cortex. The second is the subventricular zone (SVZ), which is located adjacent to the VZ and basally toward the surface of the neocortex. The VZ comprises apical radial glial cells (aRGCs), which integrate into the apical junctional belt and extend long basal processes toward the pial surface (Malatesta et al., 2000; Miyata et al., 2001; Noctor et al., 2001; Sun and Hevner, 2014, Figure 1). After the onset of neurogenesis, most aRGCs give rise to a secondary progenitor cell population in the SVZ, namely, basal intermediate progenitor cells (bIPs). bIPs demonstrate a multipolar morphology, delaminate from the apical junctional belt, and produce neurons after a limited number of cell divisions. In rodents, a subset of neocortical neurons are derived from the bIPs (Letinic et al., 2002; 


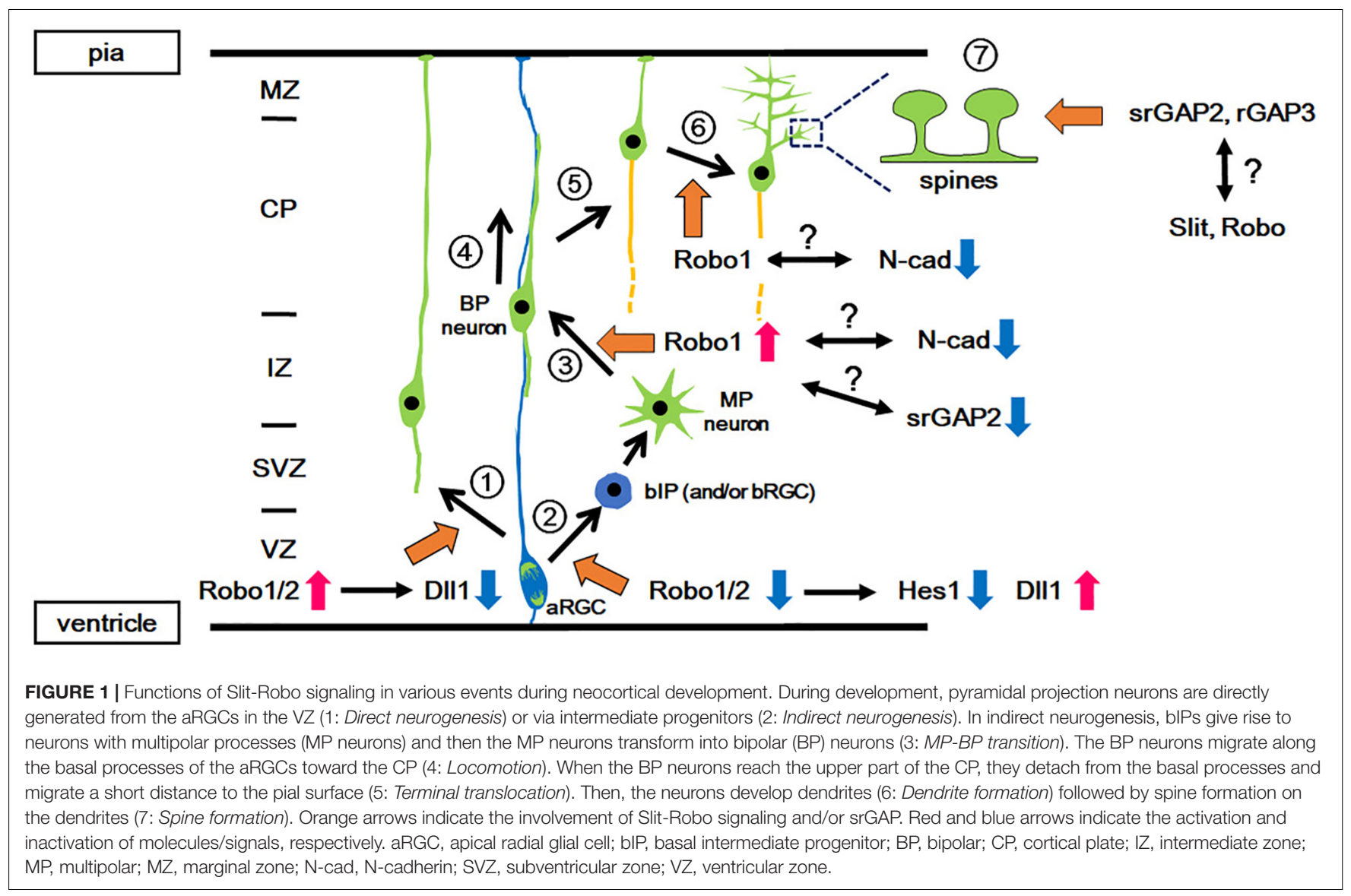

Haubensak et al., 2004; Kowalczyk et al., 2009; Petros et al., 2015; Tyler et al., 2015; Vasistha et al., 2015). Notably, in gyrencephalic mammals, including humans, non-human primates, and ferrets, there is an additional type of basal progenitor cell that demonstrates a radial glia-like morphology, namely, the basal RGCs (bRGCs; also called outer radial glial cells) (Lui et al., 2011; Wang et al., 2011; Sun and Hevner, 2014; Namba and Huttner, 2017; Miller et al., 2019; Cárdenas and Borrell, 2019). bRGCs divide extensively and produce a large number of neurons, and therefore, expansion of the neocortex is thought to correlate with the presence of bRGCs.

In mice, after the onset of neurogenesis, neurons generated from aRGCs migrate radially toward the marginal zone (MZ) through direct somal translocation by processes that extend from the soma to the pial surface (Figure 1 and Nadarajah et al., 2001). Subsequently, neurons arise from the bIPs, which demonstrate a multipolar morphology, and undergo repeated extension and retraction of their multiple thin processes in the intermediate zone (IZ) (Noctor et al., 2001; Tabata and Nakajima, 2003). The multipolar neurons first transform into bipolar neurons by extending a trailing process, followed by the formation of a leading process in the IZ and subplate (SP) (Hatanaka and Yamauchi, 2013; Namba et al., 2014). These bipolar neurons migrate radially toward the pial surface through the IZ and the cortical plate
(CP), through a locomotion mode using radial glial fibers as a scaffold (Rakic, 1972; Nadarajah et al., 2001). Once the leading processes enter the $\mathrm{MZ}$, the soma of migrating neurons translocate rapidly for a short distance toward the MZ (terminal translocation) (Nadarajah et al., 2001). Late-born neurons migrate past the earlier-born neurons that have settled in the $\mathrm{CP}$, and therefore laminar formation proceeds in an insideout manner.

Proper leading and trailing process formation and the subsequent migration of neurons are crucial for the establishment of neural networks. It has been shown that such neuronal morphogenesis and migration are regulated by environmental cues, including axon guidance molecules and cell adhesion molecules (Kawauchi, 2012; Inamura et al., 2012; Namba et al., 2015; Cadwell et al., 2019). Abnormalities in neuronal migration cause neuronal migration disorders, including lissencephaly, heterotopia, and focal cortical dysplasia (Guerrini and Parrini, 2010; Roberts, 2018). On the other hand, subtle alterations in neuronal migration cause mild changes in lamination and circuit formation, which lead to epilepsy and neuropsychiatric disorders, including autism, schizophrenia, and dyslexia (Cascella et al., 2009; Poelmans et al., 2011; Peterson and Pennington, 2012; Katsarou et al., 2017; Varghese et al., 2017; Keller et al., 2017).

In this review, we focus on Slit and Robo, which were originally identified as axon guidance molecules, and 
discuss the novel roles of Slit-Robo signaling in neocortical development. We highlight the pleiotropic functions of Slit-Robo signaling beyond axon guidance, by focusing on their new roles in the proliferation, migration, and maturation of cortical neurons during development, and further discuss the involvement of Slit-Robo signaling in human neurodevelopmental disorders.

\section{MOLECULAR PATHWAY OF SLIT-ROBO SIGNALING}

\section{Slit Ligands and Robo Receptors}

Slit and Robo were first identified by screening of Drosophila mutants demonstrating abnormal projections of commissural axons in the central nervous system (Rothberg et al., 1988; Seeger et al., 1993). Slit is a protein that is secreted by midline glial cells, and Robo receptors are expressed in commissural axons (Rothberg et al., 1990; Kidd et al., 1998). Slit molecules act via binding to Robo receptors to regulate axonal guidance (Brose et al., 1999; Kidd et al., 1999; Figure 2A). Because Slit molecules act as a repulsive axon guidance cue, Slit-Robo signaling enables all commissural axons to cross the midline only once, and thus ensures them to project to the contralateral side (Brose et al., 1999; Kidd et al., 1999).

Slit ligands and Robo receptors are well conserved across species, from invertebrates to vertebrates. In mammals, three Slit subtypes (Slit1-Slit3) (Holmes et al., 1998; Itoh et al., 1998; Brose et al., 1999; Yuan W. et al., 1999) and four Robo subtypes (Robo1-Robo4) (Kidd et al., 1998; Sundaresan et al., 1998a,b; Yuan S.S.F. et al., 1999; Huminiecki et al., 2002) have been identified. Robo receptors are single-pass transmembrane proteins and are members of the immunoglobulin superfamily of cell adhesion molecules (IgCAMs), containing immunoglobulinlike (Ig) domains and fibronectin type III (FNIII) domains (Figure 2A). Upon binding to Slit through the Ig domains, the Robo receptor transduces intracellular signals (Brose et al., 1999; Liu et al., 2004). Whereas the role of SlitRobo signaling in axon guidance is conserved from Drosophila to mammals (Bagri et al., 2002; Andrews et al., 2006; Fouquet et al., 2007; López-Bendito et al., 2007; Unni et al., 2012), several additional roles of Slit-Robo signaling have been identified in mammals. Studies have shown that Robomediated signaling is required for the proliferation of neural progenitor cells, as well as for the migration and morphological differentiation of cortical neurons (Andrews et al., 2006, 2008; Barber et al., 2009; Hernández-Miranda et al., 2011; Zheng et al., 2012; Borrell et al., 2012; Gonda et al., 2013; Yeh et al., 2014; Cárdenas et al., 2018; Blockus et al., 2019). These findings support the view that Robo signaling plays important roles in addition to axonal pathfinding in the developing neocortex.

To date, several downstream signals of the Robo receptor have been identified (Ypsilanti et al., 2010; Blockus and Chédotal, 2016; Dai et al., 2019; Jiang et al., 2019; Tong et al., 2019). Here, we focus on two Slit-Robo-mediated signal transduction systems that are involved in cerebral cortex formation.

\section{Slit-Robo GTPase-Activating Protein (srGAP) in Slit-Robo Signaling}

One of the downstream signal pathways of Slit-Robo is mediated by the Rho family of small GTPases (Wong et al., 2001; Hu et al., 2005, Figure 2B). Using yeast two-hybrid screening, Wong and colleagues identified Slit-Robo GTPase-activating protein (srGAP) as a molecule that interacts with the intracellular domain (CC3 domain) of Robo (Wong et al., 2001). In mammals, four srGAPs (srGAP1, srGAP2, srGAP3, and Arhgap4) have been identified. However, in addition to the ancestral copy of $\operatorname{srGAP2}(\operatorname{srGAP2A})$, the human genome has three humanspecific paralogs of $s r G A P 2$, namely, srGAP2B, srGAP2C, and srGAP2D, which arose by gene duplications (Dennis et al., 2012; Sporny et al., 2017). All srGAPs contain three functional domains; i.e., from the N-terminus to C-terminus, the Fes-CIP4 homology BAR (F-BAR) domain, GTPase-activating protein (GAP) domain, and Src homology 3 (SH3) domain. Each srGAP has specific binding characteristics to the Rho family small GTPases; i.e., srGAP1 interacts with Cdc42 and RhoA upon Slit stimulation (Wong et al., 2001), srGAP2 has been reported to bind to Rac1, and srGAP3 binds to both Rac1 and Cdc42 (Wong et al., 2001; Endris et al., 2002; Guerrier et al., 2009).

In experiments using a human-derived cell line, the binding of Slit to Robo was demonstrated to promote the interaction between the intracellular CC3 domain of Robo1 and srGAP1, resulting in the inactivation of $\mathrm{Cdc} 42$. Cdc42 inactivation suppresses activation of the actin-related protein (Arp)2/3 complex and neuronal Wiskott-Aldrich syndrome protein (actin polymerization regulatory protein, N-WASP), resulting in actin depolymerization. This leads to the axon repulsion and the inhibition of cell migration (Wong et al., 2001).

\section{Cell Adhesion Molecules and Slit-Robo}

In addition to srGAPs, the crosstalk between Slit-Robo signaling and cell adhesion signals is mediated by cadherins (Figure 2C). Cadherins are trans-interacting calcium-dependent cell-cell adhesion molecules, and classical cadherins (such as $\mathrm{N}$-cadherin) interact with adaptor proteins (such as catenin) to connect with the actin cytoskeleton (Nagafuchi and Takeichi, 1988; Ozawa et al., 1989; Reynolds et al., 1994). Interference of cadherin and catenin interactions leads to either increased or decreased adhesion depending on the context (Mège et al., 2006).

The binding of Slit to the Robo receptor induces an interaction between the Robo receptor and $\mathrm{N}$-cadherin-Cable complex via Abelson (Abl) kinase, which binds to the intracellular domain (CC3) of Robo. This Robo and N-cadherin interaction leads to the phosphorylation of $\beta$-catenin by Abl, and thereby phosphorylated $\beta$-catenin is detached from $\mathrm{N}$-cadherin. This, in turn, weakens $\mathrm{N}$-cadherin-mediated cell adhesion. The phosphorylated $\beta$-catenin translocates to the nucleus and activates transcription (Rhee et al., 2002, 2007). The signal transduction of Robo receptors depends on its cytoplasmic interactors: the CC3 domain of Robo1 interacts with the SH3 domain of srGAPs in addition to the SH3 domain of Abl 
A

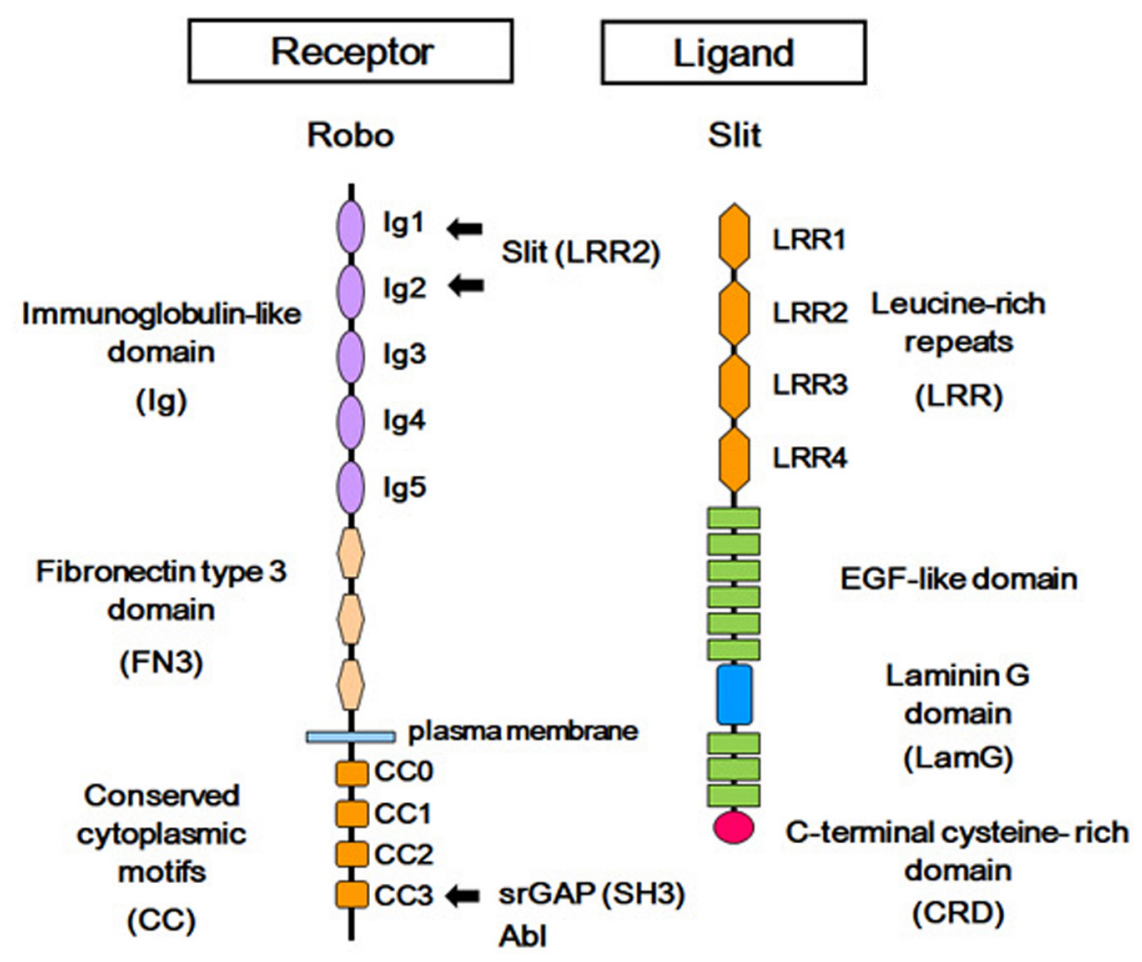

B

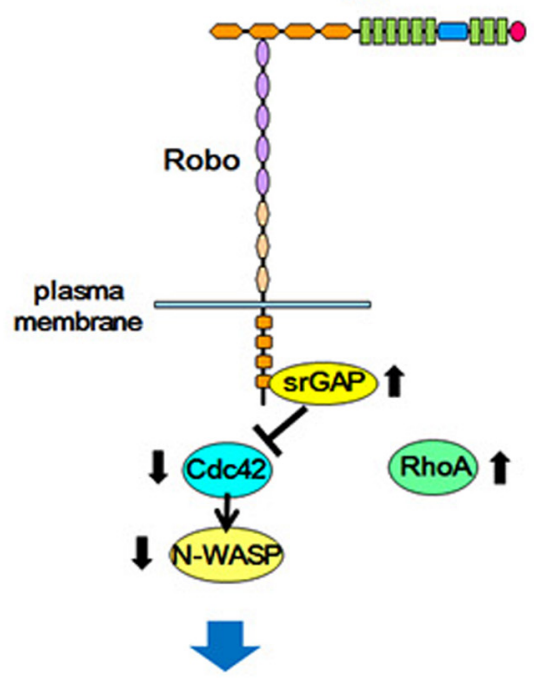

Actin polymerization $\mathbf{\downarrow}$
C

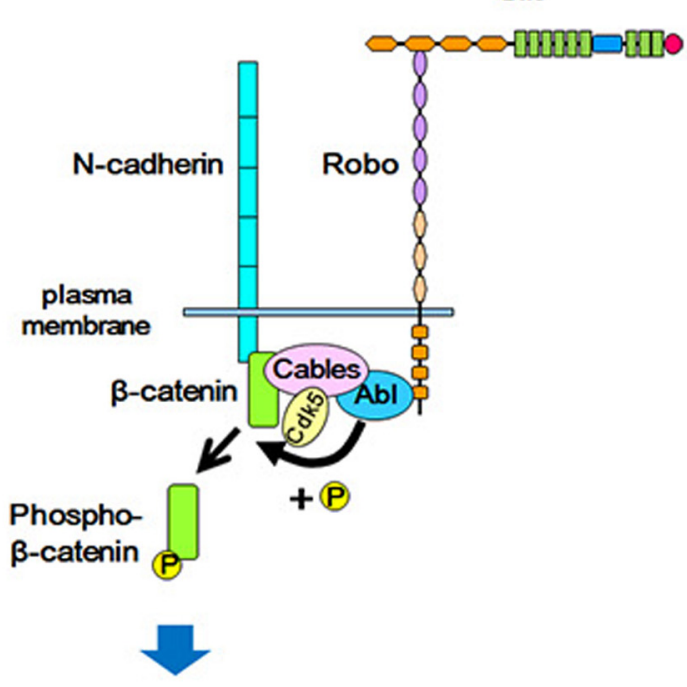

Adhesion $\downarrow$

\section{Repulsion of axon $\mathbf{t}$}

FIGURE 2 | Structures of Slit/Robo, and the Slit-Robo signaling pathway. (A) The Robo receptor contains five immunoglobulin-like domains (Ig), three fibronectin type III domains (FN3), and four conserved cytoplasmic domains (CC). Slit is a secreted glycoprotein and a major ligand of the Robo receptor. Slit contains four domains consisting of leucine-rich repeats (LRR), several EGF-like sequences, a laminin-G domain (LamG), and a C-terminal cysteine-rich domain (CRD). The LRR2 domain of Slit interacts with the lg1 and Ig2 domains of Robo, and the SH3 domain of srGAPs and Abl kinase interacts with the CC3 domain of Robo. (B) The extracellular interaction between Slit and Robo increases the binding of srGAP with Robo, resulting in the activation of srGAP. Activated srGAP induces GTP hydrolysis of Cdc42, and therefore inactivates Cdc42. Inactivated Cdc42 is unable to stimulate actin polymerization via the downstream effector of Cdc42 (N-WASP). This in turn leads to actin depolymerization and repulsion of the axon. (C) Binding of Slit to Robo results in the interaction between Abelson (Abl) and Cable, which leads to tyrosine phosphorylation of $\beta$-catenin by Abl. This phosphorylation reduces the affinity between $\beta$-catenin and $\mathrm{N}$-cadherin, and attenuates $\mathrm{N}$-cadherin-mediated adhesion. 
(Wong et al., 2001), suggesting that these two signal mediators act competitively via the same $\mathrm{SH} 3$ domain.

\section{SLIT-ROBO SIGNALING IN NEURAL PROGENITOR CELLS}

\section{Effects of Slit-Robo Signaling on Neural Progenitor Cell Proliferation}

During the early stages of cortical development, multiple signaling pathways regulate the proliferation and division modes of cortical progenitor cells. In this context, studies using Robo mutant mouse lines have implicated the roles of Slit-Robo signaling in controlling the balance between cell proliferation and differentiation.

Borrell's group reported that Slit-Robo signaling is involved in the proliferation-differentiation balance of neural progenitor cells (Borrell et al., 2012, Figure 1). Robo1/Robo2 expression is detected in the VZ. Loss of Robol/2 signaling leads to a decrease in the number of aRGCs and a concomitant increase in the number of basally located cells expressing the bIP marker Tbr2. However, these Tbr2-expressing cells retain apical processes and are integrated into the ventricular (apical) surface, suggesting that Robo signaling regulates two events, i.e., the production of intermediate progenitors (IPs) from aRGCs and their delamination from the apical junction belt.

The increased number of basally located progenitors in the neocortex of Robo1/Robo2-deficient mice is largely consistent with another report using distinct Robo1/Robo2 mutant mice (Yeh et al., 2014). However, Yeh et al. reported that the number of aRGCs is increased in Robol/Robo2 mutant mice (Yeh et al., 2014). This discrepancy between the two studies may be due to the different mutant mouse lines used. The former used a hypomorphic Robol mutant, in which Igdomain 1 and half of Ig-domain 2, which are the domains responsible for Slit binding, are still expressed (Long et al., 2004; López-Bendito et al., 2007), whereas the latter study used a null mutant mouse line ( $\mathrm{Lu}$ et al., 2007; Andrews et al., 2008). Interestingly, treatment of cortical progenitor cells with the extracellular domain of Robol resulted in a reduction in the number of progenitor cells expressing the aRGC marker Pax6 (Yeh et al., 2014). Thus, the remaining Ig domains in the hypomorphic Robol mutant mice may affect the number of aRGCs.

The function of Robo in cortical progenitor cells has been mediated by a crosstalk between Robo signaling and Hes1, which is a transcription factor acting downstream of Notch (Borrell et al., 2012, Figure 1). Notch is a transmembrane protein that is known to promote neuroepithelial cell to aRGC transition, and inhibits the production of IPs from aRGCs (Gaiano et al., 2000; Mizutani et al., 2007; Ohata et al., 2011; Martynoga et al., 2012). Upon Notch activation, its intracellular domain is cleaved and translocates into the nucleus to induce transcriptional activation of its effector gene Hes1 (Kageyama et al., 2019). As the neocortex of Robo mutant mice show reduced expression of Hes1, Robo signaling is thought to activate Hes1. Given that transcriptional activation of Hes 1 by Robo2 was observed in a cell line that lacks Notch expression, the activation of Hes1 is independent of Notch activation (Borrell et al., 2012). Furthermore, Hes 1 activation is also induced by Robo2 lacking the CC3 domain, which was previously identified to be the domain to which Robo-interacting proteins bind. These results suggest that other molecules may mediate Hes1 activation.

Altogether, Robo signaling does not affect Notch activity directly, but activates Hesl expression. This transcriptional activation of Hes1 by Robo signaling explains how the production of IPs from aRGCs is increased in Robo mutant mice (Borrell et al., 2012). In addition, Slit1/Slit2 mutant mice show a phenotype similar to that seen in Robo1/Robo2 mutant mice, which suggests that Slit1/Slit2 are candidate ligands for Robo signaling in regulating aRGC proliferation.

\section{Role of Slit-Robo Signaling in Regulating Direct vs. Indirect Neurogenesis}

The roles of Robo signaling in neuronal proliferation also implicates its roles in brain evolution (Cárdenas et al., 2018). The mammalian brain consists of distinct regions that developed at different times during evolution. The neocortex is the newest brain region that developed in mammals, whereas regions such as the olfactory bulb (OB) are conserved among vertebrates, and are thus considered to be older regions of the brain. The mode of neurogenesis differs among these regions; the neocortex undergoes indirect neurogenesis, in which aRGCs give rise to neurons via the production of bIPs, whereas $\mathrm{OB}$ neurons are produced by direct neurogenesis from the aRGCs (Díaz-Guerra et al., 2013; Luzzati, 2015; Cárdenas et al., 2018; Figure 1). Therefore, direct neurogenesis is assumed to be an evolutionarily older mode of neurogenesis, whereas indirect neurogenesis is an evolutionarily newer mode.

This difference in neurogenic modes appears to also be regulated by the level of Slit-Robo signaling. Robo1/Robo2 are expressed at higher levels in the $\mathrm{OB}$ than in the neocortex during the early stages of neurogenesis (Cárdenas et al., 2018). High expression levels of Robo1/Robo2 lead to direct neurogenesis, whereas low expression levels of Robo1/Robo2 in the neocortex is required for maintaining indirect neurogenesis (Cárdenas et al., 2018). As Robo1/Robo2 induce the expression of the Notch ligands Jag1 and Jag2, but suppress the expression of another Notch ligand, Dll1 (Cárdenas et al., 2018), Robo regulates direct vs. indirect neurogenesis via the modulation of Notch ligand expression.

A comparative study of the reptile, bird, and mammalian telencephalon showed a negative correlation of Robo expression to the amount of indirect neurogenesis. That is, the highest level of Robo expression and the lowest amount of indirect neurogenesis were observed in reptiles, a moderate level of Robo expression and moderate amount of indirect neurogenesis were found in birds, and the lowest level of Robo expression 
and the highest amount of indirect neurogenesis were detected in mammals (Cárdenas et al., 2018). Taken all together, Robo regulates the mode of neurogenesis and its low expression level enables neocortical progenitor cells to increase in number, which finally results in expansion of the telencephalon.

\section{SLIT-ROBO SIGNALING IN NEURONAL MIGRATION}

Excitatory projection neurons in the neocortex migrate radially toward the $\mathrm{CP}$ from the VZ by radial migration (OhtakaMaruyama and Okado, 2015; Hevner, 2019; Silva et al., 2019; Figure 1). By contrast, inhibitory interneurons are generated from the ganglionic eminence (GE) and migrate tangentially to the neocortex through two distinct zones, namely, the IZ/SVZ and MZ (Pleasure et al., 2000; Lim et al., 2018; Silva et al., 2019). The migration of interneurons from outside of the neocortex is another determinant of the number of neurons in the neocortex. Next, we describe the requirement of Slit-Robo signaling in these two migration modes.

\section{Slit-Robo Signaling in Interneuron Migration}

Several axon guidance molecules have been shown to regulate the tangential migration of inhibitory neurons (Zhu et al., 1999; Marín et al., 2001; Hirschberg et al., 2010). In the embryonic neocortex, Slit1 is expressed in the VZ and SVZ of the lateral and medial ganglionic eminences (Yuan W. et al., 1999; Bagri et al., 2002; Marillat et al., 2002), and has been suggested to regulate interneuron migration by repelling interneurons toward the neocortex (Zhu et al., 1999). However, Marín et al. (2003) show that the distribution of interneurons in the neocortex is unaffected in the absence of Slit1 and Slit2, suggesting that Slit is dispensable for the tangential migration of interneurons toward the neocortex.

Robol has been reported to regulate the migration of interneurons (Andrews et al., 2006). The Robol protein is detected in the SVZ of the GE and the MZ, and the lower IZ of the neocortex, where interneurons tangentially migrate to the neocortex (Andrews et al., 2006). Interneurons are aberrantly found in the striatum of Robo1-knockout mice (Andrews et al., 2006), which was not observed in Slit1- and Slit2-knockout mice (Marín et al., 2003). These data suggest that Robo signaling regulates interneuron migration through a Slitindependent mechanism. One possibility is a signal crosstalk between Robo signaling and Sema-Neuropilin (Nrp)/Plexin signaling. A previous study showed that Robol does not directly interact with Sema, but binds to Nrp1 in trans via the region including the first two Ig domains, which is known to bind to Slit molecules (Liu et al., 2004). Interestingly, interneurons in Nrp1-knockout mice demonstrate a phenotype similar to that of Robo1-knockout mice (Marín et al., 2001; Tamamaki et al., 2003). This phenotype may be due to the lack of a physical interaction between Robol and Nrp1, or the reduction in Nrp1 expression found in the interneurons of Robo1-knockout mice (Hernández-Miranda et al., 2011).

\section{Slit-Robo Signaling in the Radial Migration of Projection Neurons}

In addition to the role of Slit-Robo signaling in the migration of interneurons, the dynamics of Robol expression in cortical layer neurons during development indicated the roles of SlitRobo signaling in the radial migration of neocortical projection neurons (Marillat et al., 2002; Whitford et al., 2002; Gonda et al., 2013).

Indeed, knockdown of Robo1 in layer II/III neurons demonstrates a delay in their radial migration, particularly in their migration from the IZ to the CP (Gonda et al., 2013, Figure 1). This phenotype resembles that of $\mathrm{N}$-cadherin overexpression and $\mathrm{N}$-cadherin knockdown in migrating neurons, both of which caused a delay in neuronal migration (Kawauchi et al., 2010; Jossin and Cooper, 2011). In addition, the proper regulation of $\mathrm{N}$-cadherin-mediated cell adhesion by controlling $\mathrm{N}$-cadherin turnover in the plasma membrane of neurons was shown to be crucial for neuronal migration from the IZ to the CP (Kawauchi et al., 2010). As Robo1 inhibits the interaction between $\mathrm{N}$-cadherin and $\beta$-catenin (Rhee et al., 2002, 2007), which may lead to N-cadherin endocytosis, Robo1 may regulate radial migration, possibly by attenuating $\mathrm{N}$-cadherin-mediated cell adhesion. This possibility requires further investigation. Furthermore, there is still the open question of whether the delay in migration is dependent or independent of Slit.

Robo4 has also been reported to regulate the radial migration of layer II/III neurons (Zheng et al., 2012). Unlike Robo1knockdown neurons, Robo4-knockdown neurons cannot migrate into the $\mathrm{CP}$, and are retained in the white matter until at least postnatal day 20. Robo4-knockdown neurons do not show substantial changes in their transition from a multipolar to bipolar morphology, suggesting that Robo4 does not play a role in the polarization of neurons (La Fata et al., 2014; Barnat et al., 2017; Zhang et al., 2018). However, Robo4-knockdown neurons have leading processes with an aberrant orientation, suggesting that Robo4 regulates the interaction between the basal processes of aRGCs and migrating neurons. One possibility is that Robo4 acts as a cell adhesion molecule, similar to other IgCAMs.

In addition to the Robol and Robo4 receptors, srGAPs, which are the downstream effectors of Slit-Robo signaling, also function to regulate migration in the developing forebrain. Inhibition of srGAP1 activates Cdc42 in neurons migrating from the anterior SVZ of the neonatal forebrain and blocks Slit-mediated repulsion (Wong et al., 2001). srGAP2 expression becomes prominent in the $\mathrm{CP}$ of the neocortex from the late neurogenic period (embryonic day 16.5). Suppression of srGAP2 expression in neocortical neurons reduced the branching of leading processes, resulting in the promotion of radial migration (Guerrier et al., 2009, Figure 1). The expression of srGAP3, as well as Robo1, is decreased in the neocortex of Ngn2-knockout mice (Schuurmans et al., 2004; Mattar et al., 2004), which exhibits a delay in neuron migration (Hand et al., 2005), suggesting that Robo signaling 
and srGAP3 regulate cell migration. This possible involvement of srGAP3 in cell migration is further supported by another study that showed the abnormal migration of progenitor cells in the postnatal srGAP3-knockout mouse brain (Kim et al., 2012).

\section{Robo Signaling in the Terminal Positioning of Cortical Neurons}

The terminal positioning of excitatory projection neurons takes place in the superficial region of the $\mathrm{CP}$, designated as the primitive cortical zone (PCZ) (Sekine et al., 2011). Immature neurons undergo terminal translocation in the PCZ to complete their final positioning (Sekine et al., 2011). The terminal positioning process is known to be regulated by two distinct mechanisms (Sekine et al., 2012; Gonda et al., 2013). The first is terminal translocation, which is a mode of neuronal migration regulated by reelin, a classical secreted factor that is deposited in the MZ and is required for laminar formation (Kubo et al., 2010; Hirota et al., 2018). Terminal translocation has been shown to be independent of the radial glial scaffold (Nadarajah et al., 2001), and therefore the attenuation of N-cadherin-mediated cell adhesion between neurons and the radial glial scaffold may be important. Consistent with this view, N-cadherin protein expression is low in the PCZ (Kawauchi et al., 2010, Figure 1). As Robol attenuates $\mathrm{N}$-cadherin-mediated cell adhesion by inducing the phosphorylation of $\beta$-catenin, which promotes the detachment of $\beta$-catenin from $\mathrm{N}$-cadherin (Rhee et al., 2002, 2007), the internalization and subsequent proteolysis of $\mathrm{N}$-cadherin might be increased in the PCZ where Robol is highly expressed.

The second mechanism is regulation through dendrite formation. In the PCZ, terminally translocated neurons stabilize the leading process, which eventually differentiates into an apical dendrite of a pyramidal neuron (O'Dell et al., 2015, Figure 1). Together with apical dendrite extension, the cell soma of the neuron moves down to the CP. In contrast, Robol-knockdown neurons migrate through the $\mathrm{CP}$ and reach the MZ-CP border; however, these neurons accumulate there (Gonda et al., 2013). This phenotype indicates that terminal translocation is not affected; however, dendrite formation is impaired in Robo1-knockdown cells. The extension of apical dendrites toward the $\mathrm{MZ}$ creates a space for terminally translocated neurons to pass through the earlier-arriving resident neurons. In agreement with this notion, the insideout layering pattern is disrupted in the cortex of Robo1knockdown mice, suggesting that a defect in the terminal positioning of cortical layer neurons is due to abnormal dendrite formation.

\section{ROLES OF SLIT-ROBO SIGNALING IN DENDRITE DEVELOPMENT}

Dendritic patterning is a crucial developmental process in neocortical circuit formation and function. The dendritic development of neocortical projection neurons may be controlled by factors in the MZ (Polleux et al., 2000; O'Dell et al., 2012), because dendrites undergo dynamic changes after neurons reach the superficial part of the cortex and initiate differentiation (O’Dell et al., 2015, Figure 1).

During this process, Robol is required for proper apical dendrite formation (Gonda et al., 2013), however, the mechanisms by which Robol regulates the morphological development of differentiating cortical neurons remains unknown. One possible role of Robol is that it acts as a cell adhesion molecule similar to other IgCAMs, which are known to regulate dendrite formation during development (Moresco et al., 2005; Seong et al., 2015; Parcerisas et al., 2020). The other possibility is that Robo acts to attenuate $\mathrm{N}$-cadherin-mediated cell adhesion, as described above (Figures 1, 2C).

In vitro studies have demonstrated that Slit1 also promotes dendrite formation in both pyramidal and non-pyramidal neurons. Inhibition of the binding of Slit to Robo receptors by Robo1 and Robo2 ectodomains suppressed dendrite growth and branching in pyramidal and non-pyramidal neurons (Whitford et al., 2002). Furthermore, a dominant-negative form of Robo1 inhibited dendritic branching in cultured neurons (Whitford et al., 2002). In contrast, Robol knockdown increased the number of apical dendrites of layer II/III neurons in vivo (Gonda et al., 2013). These differences may be due to the experimental conditions, as the former study was performed in cultured neurons (Whitford et al., 2002) lacking an in vivo microenvironment, whereas the latter study analyzed neocortical neurons in vivo, which maintains tissue polarity and a relevant microenvironment (Gonda et al., 2013). An alternative explanation is the difference of neuronal types between layer $\mathrm{V}$ neurons (Whitford et al., 2002) and layer II/III neurons (Gonda et al., 2013).

Slit-Robo signaling also affects the early neurite outgrowth of cortical interneurons in vivo (Andrews et al., 2008). Migrating interneurons in the SP and SVZ/IZ of Robo1-knockout mice have more processes and longer neurites compared with the interneurons of WT mice. As Slit1/Slit2 double-knockout mice showed a marked increase in process length and neurite number, Slit1/2-Robo1 signaling acts as a negative regulator of neurite outgrowth in migrating interneurons. Taken together, SlitRobo signaling inhibits the overgrowth of neurites, which in turn ensures the proper dendritic formation and migration of interneurons.

One of the downstream molecular mechanisms underlying Slit-Robo-mediated dendrite formation involves srGAPs. srGAPs are the downstream mediators of Robo, and have at least two distinct roles in neurite outgrowth. srGAPs, which are Rho family small GTPase inhibitors, regulate cytoskeletal dynamics, which is crucial for neurite outgrowth (Figure 2B). Because each srGAP demonstrates a specificity to particular Rho family small GTPases, they play distinct roles in neurite outgrowth, for example, srGAP3 inhibits neurite outgrowth via Rac1 inactivation (Soderling et al., 2002), whereas srGAP2 has been reported to promote neurite outgrowth (Guerrier et al., 2009). As srGAP2 also inactivates Rac1, the functional difference between srGAP2 and srGAP3 cannot be explained by their GAP specificities, and may be owing to another domain in srGAPs, namely, the F-BAR domain (Figure 3A). 
A

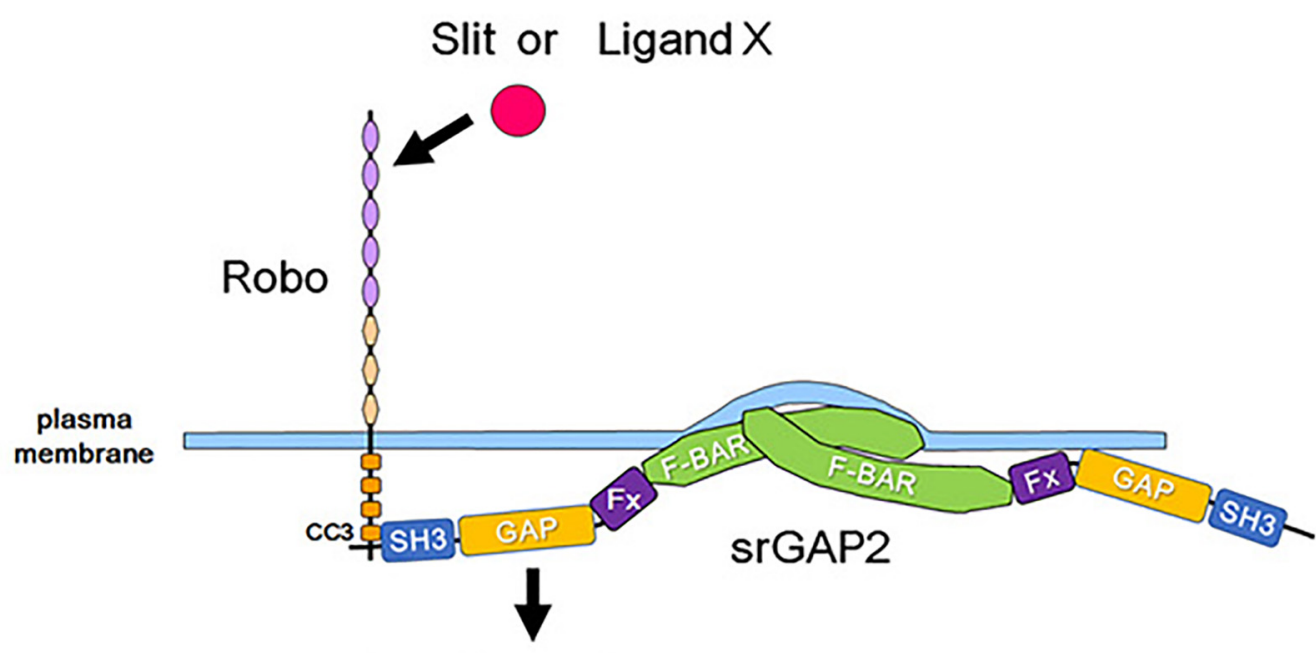

Signaling pathway

B

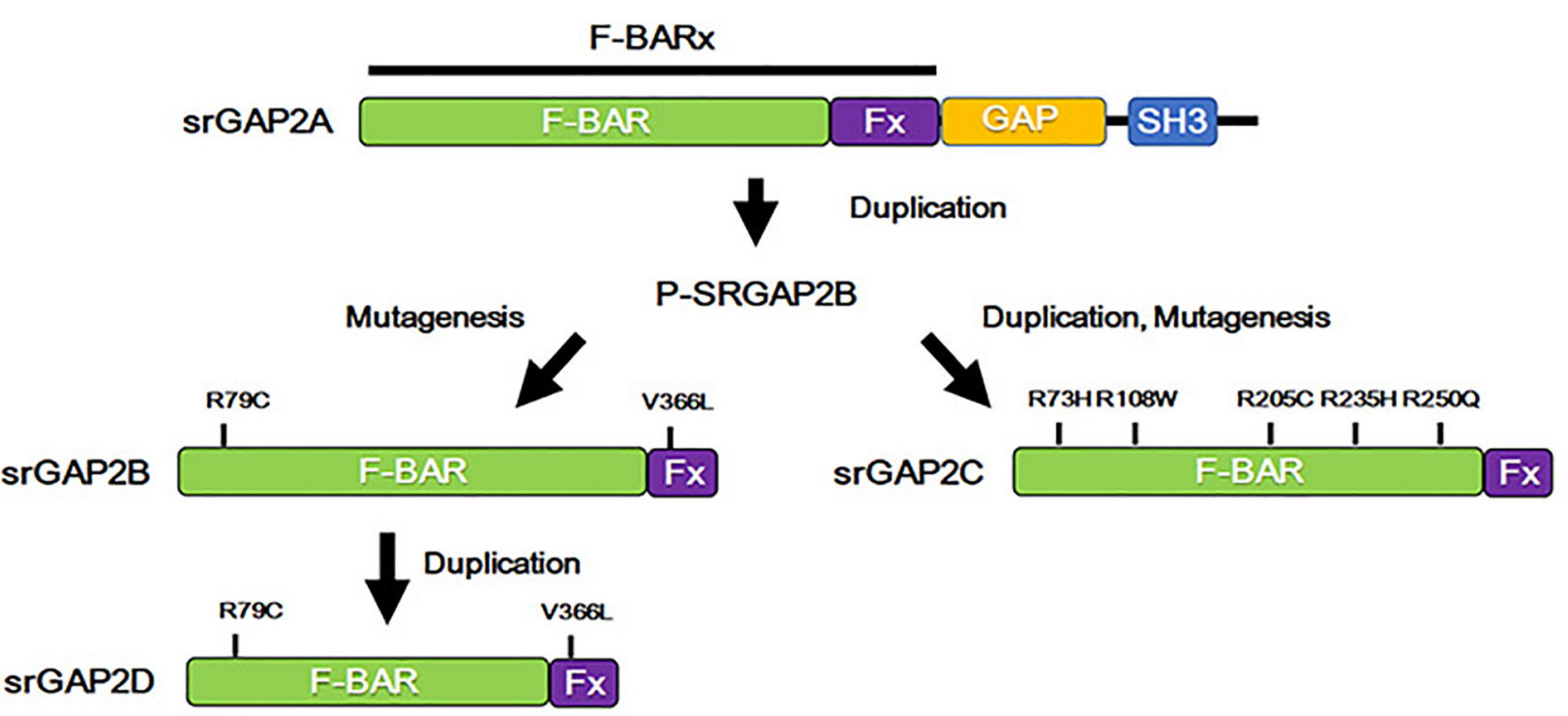

FIGURE 3 | Role of srGAP2 in membrane protrusion, and evolutionary history of srGAP2. (A) By the binding of Slit or some other stimulation, the CC3 domain of Robo interacts with the $\mathrm{SH} 3$ domain of srGAP2. srGAP2 forms a homodimer via its F-BAR domain and directly binds to the plasma membrane, inducing filopodia-like protrusions. (B) srGAP contains an amino-terminal extended F-BAR (F-BARX), GAP, and SH3 domains. srGAP2A is the ancestral form, and srGAP2B, srGAP2C, and srGAP2G evolved into their present forms after several evolutionary steps of duplication and/or mutagenesis.

The F-BAR domain normally induces invagination of the plasma membrane; however, the F-BAR domain of srGAP2 demonstrates a function of the I-BAR domain, that is, the induction of filopodia formation by outward bending of the plasma membrane (Guerrier et al., 2009). Consistent with this function, srGAP2 promotes filopodia formation and subsequent neurite outgrowth in cultured cortical neurons (Guerrier et al., 2009; Coutinho-Budd et al., 2012). In contrast, the filopodia-forming function of srGAP3 appears to be weaker than that of srGAP2. Furthermore, srGAP1 prevents filopodia formation (Coutinho-Budd et al., 2012). Therefore, a balance in the activities mediated by the GAP and the BAR domain may determine the effect of srGAPs on neurite outgrowth. As the activity of the GAP domain is regulated by Slit-Robo signaling (Wong et al., 2001), the presence of Slit-Robo signaling might enable the function of GAPs to dominate over the function of the BAR domain. 


\section{SrGAP AND ROBO SIGNALING IN SPINE FORMATION}

Dendritic filopodium is a structure found in the early stages of spine formation, which matures into a dendritic spine. Therefore, filopodium formation is thought to be crucial for the onset of spine formation. As mentioned above, srGAPs are known to regulate filopodium formation and thus control spine formation in neurons.

srGAP2 is detected in the spine head of excitatory synapses in neocortical projection neurons and promotes spine maturation (Charrier et al., 2012, Figure 3A). Interestingly, human-specific paralogs of srGAP2, namely, srGAP2B, srGAP2C, and srGAP2D arose by gene duplications during human evolution (Dennis et al., 2012, Figure 3B). Because of partial gene duplication, srGAP2C retains only a part of the F-BAR domain. srGAP2C binds to an ancestral paralog of srGAP2A, and inhibits the function of srGAP2A in spine formation (Charrier et al., 2012; Fossati et al., 2016; Sporny et al., 2017).

In addition, srGAP3 was initially reported as mental disorderassociated GAP protein, also known as WAVE-associated Rac GTPase-activating protein (WRP), through the analysis of a female patient with $3 p$ deletion syndrome who had hypotonia and severe intellectual disability (Endris et al., 2002). srGAP3 interacts with a scaffold protein for actin remodeling, WAVE1, and inhibits Rac1 activity (Soderling et al., 2002). Because either the inhibition of or activation of Rac1 leads to abnormal spine formation (Costa et al., 2020), precise regulation of Rac1 activity is crucial for normal spine formation. Consistent with this notion, both a reduced interaction between srGAP3 and WAVE-1 and knockout of srGAP3 have been shown to decrease the number of spines (Soderling et al., 2007; Carlson et al., 2011).

Recently, the association between Robo and spine formation has been reported. Robo2 is localized at the postsynaptic membrane of hippocampal CA1 pyramidal neurons, and directly binds to presynaptic neurexin irrespective of Slit (Blockus et al., 2019). This binding promotes spine formation and subsequent excitatory synapse formation.

In summary, srGAPs play a role in spine formation through its Rho GAP domain and/or F-BAR domain (Figure 3A). However, the involvement of Slit-Robo in the functions of srGAPs needs further investigation. One possibility is that Robo determines srGAP localization at the plasma membrane and therefore regulates the site of spine formation. Furthermore, it will be interesting to clarify the roles of Slit-Robo and srGAP signaling in the diversification of spine formation among different functional regions of the neocortex (Benavides-Piccione et al., 2002; Konur et al., 2003; Sasaki et al., 2010).

\section{SLIT-ROBO SIGNALING AND NEUROPSYCHIATRIC DISORDERS}

Abnormal development of the neocortex affects neural circuit formation and causes neuropsychiatric disorders. Here, we discuss two etiologies known to be caused by abnormalities in Slit-Robo signaling, i.e., dyslexia and autism spectrum disorder (ASD).

\section{Robo and Dyslexia}

ROBO1 and ROBO2 have been associated with dyslexia (NopolaHemmi et al., 2001; Stein et al., 2004). ROBO1 and ROBO2 genes are mapped at the dyslexia susceptibility loci DYX5, which is located on chromosome 3 (3p12-q13). Silent and $3^{\prime}$ UTR SNPs of $R O B O 1$ and a translocation $\mathrm{t}(3 ; 8)$ (p12; q11) that causes reduced $R O B O 1$ transcription were found in individuals with dyslexia (Hannula-Jouppi et al., 2005). Furthermore, a study analyzing post-mortem brains of dyslexic subjects demonstrated the presence of abnormal microgyria in the left temporal speech region and ectopic neurons in the subcortical white matter (Galaburda and Kemper, 1979), which are thought to be caused by ectopic neuronal positioning.

However, recently, a magnetic resonance imaging study of children with dyslexia demonstrated the abnormal morphology of neurites in the language-associated regions of the neocortex (Caverzasi et al., 2018). In line with these observations, reduced expression of Robol in the embryonic mouse neocortex was shown to delay neuronal migration during development, followed by abnormal dendrite formation leading to subsequent impairment in the terminal positioning of neurons (Gonda et al., 2013).

Taken all together, the dyslexic phenotype in patients with ROBO1 mutations may be caused by the abnormal formation of dendrites and terminal positioning of neurons. As dendrite formation and terminal positioning of neurons are potentially regulated by signals from the MZ and occur during the neonatal period, an interaction between ROBO1 and Slit or unknown molecules that reside in the MZ during the neonatal period might be important. Altogether, RОВО plays a crucial role in human neocortical development by regulating dendrite formation and neuron positioning, and such abnormalities occurring in language-associated regions can lead to dyslexia.

\section{Slit-Robo Signaling and ASD}

In addition to dyslexia, the downregulation of ROBO expression has also been associated with ASD, presumably through the modulation of serotonin levels in the neocortex.

Serotonin reuptake by serotonin transporters is crucial for maintaining normal levels of serotonin in the neocortex. Dysfunctions of serotonin transporters and resultant high serotonin levels are observed in ASD patients (Schain and Freedman, 1961; Muller et al., 2016). As Robo has been shown to promote serotonin transporter expression in Drosophila (Couch et al., 2004), and the expression of ROBO1, ROBO2, ROBO3, and $\mathrm{ROBO} 4$ was reduced in patients diagnosed as having ASD (Anitha et al., 2008), decreased ROBO expression might increase serotonin level, which is associated with ASD. As excess serotonin in the developing mouse neocortex is known to affect the migration of both pyramidal neurons and interneurons (Riccio et al., 2009, 2011), decreased ROBO expression might impair neuronal migration in a non-cell autonomous manner in addition to the cell-autonomous manner (see section "Slit-Robo Signaling in Neuronal Migration"). 
In addition, mutations in srGAPs are associated with intellectual and cognitive disabilities (Saitsu et al., 2012; Waltereit et al., 2012; Bertram et al., 2016). The disruption of SRGAP2 expression was found in patients diagnosed with West syndrome, who demonstrate intellectual disability (Saitsu et al., 2012). A microdeletion of 1q32.1, where the SRGAP2 gene is localized, causes Van der Woude syndrome accompanied with intellectual disabilities (Rincic et al., 2016). In addition, rare copy number variations of SRGAP2C, a human-specific paralog of $s r G A P 2$, was identified in patients with ASD and intellectual disability (Dennis et al., 2012, Figure 3B). srGAP3-deficient mice demonstrate several behavioral abnormalities, including intellectual disabilityassociated behaviors and autism-associated behaviors (Kim et al., 2012; Waltereit et al., 2012; Koschützke et al., 2015; Bertram et al., 2016). srGAPs have been shown to play important roles in spine formation, and srGAP mutations are thought to cause intellectual disabilities, likely via abnormal spine formation.

\section{CONCLUSION AND PERSPECTIVES}

Whereas the roles of Slit-Robo signaling in the developing brain have been well studied regarding axon guidance, during the previous decade, new roles of Slit-Robo signaling in progenitor cell proliferation and dendritic formation have emerged. These studies have shed light on the fundamental roles of Slit-Robo signaling in multiple events of neocortical development, from the proliferation of progenitor cells to circuit formation (Figure 1).

Although the significance of Slit-Robo signaling in cortical development has been highlighted in this review, the detailed molecular mechanisms underlying Slit-Robo-mediated corticogenesis merits further investigation. As Slit molecules and Robo receptors have multiple binding partners in addition to their conventional ones, a comprehensive understanding of the Slit and Robo interactome in different cell types at different

\section{REFERENCES}

Andrews, W., Barber, M., Hernadez-Miranda, L. R., Xian, J., Rakic, S., Sundaresan, V., et al. (2008). The role of Slit-Robo signaling in the generation, migration and morphological differentiation of cortical interneurons. Dev. Biol. 313, 648-658. doi: 10.1016/j.ydbio.2007.10.052

Andrews, W., Liapi, A., Plachez, C., Camurri, L., Zhang, J., Mori, S., et al. (2006). Robol regulates the development of major axon tracts and interneuron migration in the forebrain. Development 133, 2243-2252. doi: 10.1242/dev. 02379

Anitha, A., Nakamura, K., Yamada, K., Suda, S., Thanseem, I., Tsujii, M., et al. (2008). Genetic analyses of Roundabout (ROBO) axon guidance receptors in autism. Am. J. Med. Genet. Part B Neuropsychiatr. Genet. 147, 1019-1027. doi: 10.1002/ajmg.b.30697

Bagri, A., Marín, O., Plump, A. S., Mak, J., Pleasure, S. J., Rubenstein, J. L. R., et al. (2002). Slit proteins prevent midline crossing and determine the dorsoventral position of major axonal pathways in the mammalian forebrain. Neuron 33, 233-248. doi: 10.1016/S0896-6273(02)00561-5

Barber, M., Di Meglio, T., Andrews, W. D., Hernández-Miranda, L. R., Murakami, F., Chédotal, A., et al. (2009). The role of Robo3 in the development of cortical interneurons. Cereb. Cortex 19, i22-i31. doi: 10.1093/cercor/bhp041

Barnat, M., Le Friec, J., Benstaali, C., and Humbert, S. (2017). Huntingtin-mediated multipolar-bipolar transition of newborn cortical neurons is critical for their developmental stages is essential to understand the upstream and downstream signaling networks of Slit and Robo. This in turn will help us to understand the etiology of human diseases caused by abnormalities in Robo signaling.

The recent implication of Robo signaling in brain evolution (Cárdenas et al., 2018) has provided an important direction for future studies. The association of ROBO1 with literacy (HannulaJouppi et al., 2005), which is a unique characteristic of humans, suggests that Robo signaling is involved not only in the expansion of the brain during evolution, but also in the development of higher brain functions.

Taken together, now is the time to revise our classical view of Slit-Robo signaling as a regulator of axon guidance, and build a new perspective on these key molecules in orchestrating multiple steps of neocortical circuit assembly and function.

\section{AUTHOR CONTRIBUTIONS}

YG wrote and edited the manuscript. TN and $\mathrm{CH}$ edited the manuscript. All authors reviewed, discussed, and commented on the manuscript.

\section{FUNDING}

This work was supported by a President's Discretionary Grant from Tokyo Medical University, by a KAKENHI Follow-up Grant from Tokyo Medical University, and by MEXT/JSPS KAKENHI (19K06930 and 19K08065 for YG).

\section{ACKNOWLEDGMENTS}

We thank Dr. Helena Popiel for editorial review of the manuscript.

postnatal neuronal morphology. Neuron 93, 99-114. doi: 10.1016/j.neuron. 2016.11.035

Benavides-Piccione, R., Ballesteros-Yáñez, I., DeFelipe, J., and Yuste, R. (2002). Cortical area and species differences in dendritic spine morphology. J. Neurocytol. 31, 337-346. doi: 10.1023/A:1024134312173

Bertram, J., Koschützke, L., Pfannmöller, J. P., Esche, J., van Diepen, L., Kuss, A. W., et al. (2016). Morphological and behavioral characterization of adult mice deficient for SrGAP3. Cell Tissue Res. 366, 1-11. doi: 10.1007/s00441-0162413-y

Blockus, H., and Chédotal, A. (2016). Slit-robo signaling. Development 143, $3037-$ 3044. doi: 10.1242/dev.132829

Blockus, H., Rolotti, S. V., Szoboszlay, M., Ming, T., Schroeder, A., Vennekens, K. M., et al. (2019). Synaptogenic activity of the axon guidance molecule Robo2 is critical for hippocampal circuit function. bioRxiv [Preprint], doi: 10.1101/ 840710

Borrell, V., Cárdenas, A., Ciceri, G., Galcerán, J., Flames, N., Pla, R., et al. (2012). Slit/Robo signaling modulates the proliferation of central nervous system progenitors. Neuron 76, 338-352. doi: 10.1016/j.neuron.2012. 08.003

Brose, K., Bland, K. S., Kuan, H. W., Arnott, D., Henzel, W., Goodman, C. S., et al. (1999). Slit proteins bind robo receptors and have an evolutionarily conserved role in repulsive axon guidance. Cell 96, 795-806. doi: 10.1016/S0092-8674(00) 80590-5 
Cadwell, C. R., Bhaduri, A., Mostajo-Radji, M. A., Keefe, M. G., and Nowakowski, T. J. (2019). Development and arealization of the cerebral cortex. Neuron 103, 980-1004. doi: 10.1016/j.neuron.2019.07.009

Cárdenas, A., and Borrell, V. (2019). Molecular and cellular evolution of corticogenesis in amniotes. Cell. Mol. Life Sci. 77, 1435-1460. doi: 10.1007/ s00018-019-03315-x

Cárdenas, A., Villalba, A., de Juan Romero, C., Picó, E., Kyrousi, C., Tzika, A. C., et al. (2018). Evolution of cortical neurogenesis in amniotes controlled by robo signaling levels. Cell 174, 590-606.e21. doi: 10.1016/j.cell.2018.06.007

Carlson, B. R., Lloyd, K. E., Kruszewski, A., Kim, I. H., Rodriguiz, R. M., Heindel, C., et al. (2011). WRP/srGAP3 facilitates the initiation of spine development by an inverse F-BAR domain, and its loss impairs long-term memory. J. Neurosci. 31, 2447-2460. doi: 10.1523/JNEUROSCI.4433-10.2011

Cascella, N. G., Schretlen, D. J., and Sawa, A. (2009). Schizophrenia and epilepsy: is there a shared susceptibility? Neurosci. Res. 63, 227-235. doi: 10.1016/j.neures. 2009.01.002

Caverzasi, E., Mandelli, M. L., Hoeft, F., Watson, C., Meyer, M., Allen, I. E., et al. (2018). Abnormal age-related cortical folding and neurite morphology in children with developmental dyslexia. Neuroimage Clin. 18, 814-821. doi: 10.1016/j.nicl.2018.03.012

Charrier, C., Joshi, K., Coutinho-Budd, J., Kim, J. E., Lambert, N., De Marchena, J., et al. (2012). Inhibition of SRGAP2 function by its human-specific paralogs induces neoteny during spine maturation. Cell 149, 923-935. doi: 10.1016/j.cell. 2012.03.034

Costa, J. F., Dines, M., and Lamprecht, R. (2020). The role of Rac GTPase in dendritic spine morphogenesis and memory. Front. Synaptic Neurosci. 12:12. doi: 10.3389/fnsyn.2020.00012

Couch, J. A., Chen, J., Rieff, H. I., Uri, E. M., and Condron, B. G. (2004). Robo2 and robo3 interact with eagle to regulate serotonergic neuron differentiation. Development 131, 997-1006. doi: 10.1242/dev.00962

Coutinho-Budd, J., Ghukasyan, V., Zylka, M. J., and Polleux, F. (2012). The F-BAR domains from srGAP1, srGAP2 and srGAP3 regulate membrane deformation differently. J. Cell Sci. 125, 3390-3401. doi: 10.1242/jcs.098962

Dai, C., Gong, Q., Cheng, Y., and Su, G. (2019). Regulatory mechanisms of Robo4 and their effects on angiogenesis. Biosci. Rep. 39, 1-18. doi: 10.1042/ BSR20190513

Dennis, M. Y., Nuttle, X., Sudmant, P. H., Antonacci, F., Graves, T. A., Nefedov, M., et al. (2012). Evolution of human-specific neural SRGAP2 genes by incomplete segmental duplication. Cell 149, 912-922. doi: 10.1016/j.cell.2012.03.033

Díaz-Guerra, E., Pignatelli, J., Nieto-Estévez, V., and Vicario-Abejón, C. (2013). Transcriptional regulation of olfactory bulb neurogenesis. Anat. Rec. 296, 1364-1382. doi: 10.1002/ar.22733

Endris, V., Wogatzky, B., Leimer, U., Bartsch, D., Zatyka, M., Latif, F., et al. (2002). The novel Rho-GTPase activating gene MEGAP/srGAP3 has a putative role in severe mental retardation. Proc. Natl. Acad. Sci. U.S.A. 99, 11754-11759. doi: 10.1073/pnas.162241099

Fossati, M., Pizzarelli, R., Schmidt, E. R., Kupferman, J. V., Stroebel, D., Polleux, F., et al. (2016). SRGAP2 and its human-specific paralog co-regulate the development of excitatory and inhibitory synapses. Neuron 91, 356-369. doi: 10.1016/j.neuron.2016.06.013

Fouquet, C., Meglio, T., Di Ma, L., Kawasaki, T., Long, H., Hirata, T., et al. (2007). Robo1 and Robo2 control the development of the lateral olfactory tract. J. Neurosci. 27, 3037-3045. doi: 10.1523/JNEUROSCI.0172-07.2007

Gaiano, N., Nye, J. S., and Fishell, G. (2000). Radial glial identity is promoted by Notch1 signaling in the murine forebrain. Neuron 26, 395-404. doi: 10.1016/ S0896-6273(00)81172-1

Galaburda, A. M., and Kemper, T. L. (1979). Cytoarchitectonic abnormalities in developmental dyslexia: a case study. Ann. Neurol. 6, 94-100. doi: 10.1002/ana. 410060203

Gonda, Y., Andrews, W. D., Tabata, H., Namba, T., Parnavelas, J. G., Nakajima, K., et al. (2013). Robol regulates the migration and laminar distribution of upperlayer pyramidal neurons of the cerebral cortex. Cereb. Cortex 23, 1495-1508. doi: $10.1093 /$ cercor/bhs141

Guerrini, R., and Parrini, E. (2010). Neuronal migration disorders. Neurobiol. Dis. 38, 154-166. doi: 10.1016/j.nbd.2009.02.008

Guerrier, S., Coutinho-Budd, J., Sassa, T., Gresset, A., Jordan, N. V., Chen, K., et al. (2009). The F-BAR domain of srGAP2 induces membrane protrusions required for neuronal migration and morphogenesis. Cell 138, 990-1004. doi: 10.1016/j.cell.2009.06.047

Hand, R., Bortone, D., Mattar, P., Nguyen, L., Heng, J. I. T., Guerrier, S., et al. (2005). Phosphorylation of neurogenin 2 specifies the migration properties and the dendritic morphology of pyramidal neurons in the neocortex. Neuron 48 , 45-62. doi: 10.1016/j.neuron.2005.08.032

Hannula-Jouppi, K., Kaminen-Ahola, N., Taipale, M., Eklund, R., Nopola-Hemmi, J., Kääriäinen, H., et al. (2005). The axon guidance receptor gene ROBO1 is a candidate gene for developmental dyslexia. PLoS Genet. 1:e50. doi: 10.1371/ journal.pgen.0010050

Hatanaka, Y., and Yamauchi, K. (2013). Excitatory cortical neurons with multipolar shape establish neuronal polarity by forming a tangentially oriented axon in the intermediate zone. Cereb. Cortex 23, 105-113. doi: 10.1093/cercor/bhr383

Haubensak, W., Attardo, A., Denk, W., and Huttner, W. B. (2004). Neurons arise in the basal neuroepithelium of the early mammalian telencephalon: a major site of neurogenesis. Proc. Natl. Acad. Sci. U.S.A. 101, 3196-3201. doi: 10.1073/ pnas. 0308600100

Hernández-Miranda, L. R., Cariboni, A., Faux, C., Ruhrberg, C., Cho, J. H., Cloutier, J. F., et al. (2011). Robo1 regulates semaphorin signaling to guide the migration of cortical interneurons through the ventral forebrain. J. Neurosci. 31, 6174-6187. doi: 10.1523/JNEUROSCI.5464-10.2011

Hevner, R. F. (2019). Intermediate progenitors and Tbr2 in cortical development. J. Anat. 235, 616-625. doi: 10.1111/joa.12939

Hirota, Y., Kubo, K. I., Fujino, T., Yamamoto, T. T., and Nakajima, K. (2018). ApoER2 Controls not only neuronal migration in the intermediate zone but also termination of migration in the developing cerebral cortex. Cereb. Cortex 28, 223-235. doi: 10.1093/cercor/bhw369

Hirschberg, A., Deng, S., Korostylev, A., Paldy, E., Costa, M. R., Worzfeld, T., et al. (2010). Gene deletion mutants reveal a role for semaphorin receptors of the Plexin-B family in mechanisms underlying corticogenesis. Mol. Cell. Biol. 30, 764-780. doi: 10.1128/mcb.01458-09

Holmes, G. P., Negus, K., Burridge, L., Raman, S., Algar, E., Yamada, T., et al. (1998). Distinct but overlapping expression patterns of two vertebrate slit homologs implies functional roles in CNS development and organogenesis. Mech. Dev. 79, 57-72. doi: 10.1016/S0925-4773(98)00174-9

Hu, H., Li, M., Labrador, J. P., McEwen, J., Lai, E. C., Goodman, C. S., et al. (2005). Cross GTPase-activating protein (CrossGAP)/Vilse links the roundabout receptor to Rac to regulate midline repulsion. Proc. Natl. Acad. Sci. U.S.A. 102, 4613-4618. doi: 10.1073/pnas.0409325102

Huminiecki, L., Michael, G., Steven, S., and Richard Poulsom, R. B. (2002). Magic roundabout is a new member of the roundabout receptor family that is endothelial specific and expressed at sites of active angiogenesis. Genomics 79, 547-552. doi: 10.1006/geno.2002.6745

Inamura, N., Kimura, T., Tada, S., Kurahashi, T., Yanagida, M., Yanagawa, Y., et al. (2012). Intrinsic and extrinsic mechanisms control the termination of cortical interneuron migration. J. Neurosci. 32, 6032-6042. doi: 10.1523/jneurosci.344611.2012

Itoh, A., Miyabayashi, T., Ohno, M., and Sakano, S. (1998). Cloning and expressions of three mammalian homologues of Drosophila slit suggest possible roles for Slit in the formation and maintenance of the nervous system. Mol. Brain Res. 62, 175-186. doi: 10.1016/S0169-328X(98)00224- 1

Jiang, Z., Liang, G., Xiao, Y., Qin, T., Chen, X., Wu, E., et al. (2019). Targeting the SLIT/ROBO pathway in tumor progression: molecular mechanisms and therapeutic perspectives. Ther. Adv. Med. Oncol. 11, 1-14. doi: 10.1177/ 1758835919855238

Jossin, Y., and Cooper, J. A. (2011). Reelin, Rap1 and N-cadherin orient the migration of multipolar neurons in the developing neocortex. Nat. Neurosci. 14, 697-703. doi: 10.1038/nn.2816

Kageyama, R., Shimojo, H., and Ohtsuka, T. (2019). Dynamic control of neural stem cells by bHLH factors. Neurosci. Res. 138, 12-18. doi: 10.1016/j.neures. 2018.09.005

Katsarou, A. M., Moshé, S. L., and Galanopoulou, A. S. (2017). Interneuronopathies and their role in early life epilepsies and neurodevelopmental disorders. Epilepsia Open 2, 284-306. doi: 10.1002/epi4.12062

Kawauchi, T. (2012). Cell adhesion and its endocytic regulation in cell migration during neural development and cancer metastasis. Int. J. Mol. Sci. 13, 45644590. doi: 10.3390/ijms13044564 
Kawauchi, T., Sekine, K., Shikanai, M., Chihama, K., Tomita, K., Kubo, K. I., et al. (2010). Rab GTPases-dependent endocytic pathways regulate neuronal migration and maturation through N-cadherin trafficking. Neuron 67, 588-602. doi: 10.1016/j.neuron.2010.07.007

Keller, R., Basta, R., Salerno, L., and Elia, M. (2017). Autism, epilepsy, and synaptopathies: a not rare association. Neurol. Sci. 38, 1353-1361. doi: 10.1007/ s10072-017-2974-x

Kidd, T., Bland, K. S., and Goodman, C. S. (1999). Slit is the midline repellent for the Robo receptor in Drosophila. Cell 96, 785-794. doi: 10.1016/S0092-8674(00) 80589-9

Kidd, T., Brose, K., Mitchell, K. J., Fetter, R. D., Tessier-Lavigne, M., Goodman, C. S., et al. (1998). Roundabout controls axon crossing of the CNS midline and defines a novel subfamily of evolutionarily conserved guidance receptors. Cell 92, 205-215. doi: 10.1016/S0092-8674(00)80915-0

Kim, I. H., Carlson, B. R., Heindel, C. C., Kim, H., and Soderling, S. H. (2012). Disruption of wave-associated Rac GTPase-activating protein (Wrp) leads to abnormal adult neural progenitor migration associated with hydrocephalus. J. Biol. Chem. 287, 39263-39274. doi: 10.1074/jbc.M112.398834

Konur, S., Rabinowitz, D., Fenstermaker, V. L., and Yuste, R. (2003). Systematic regulation of spine sizes and densities in pyramidal neurons. J. Neurobiol. 56, 95-112. doi: 10.1002/neu.10229

Koschützke, L., Bertram, J., Hartmann, B., Bartsch, D., Lotze, M., and von Bohlen Halbach, O. (2015). SrGAP3 knockout mice display enlarged lateral ventricles and specific cilia disturbances of ependymal cells in the third ventricle. Cell Tissue Res. 361, 645-650. doi: 10.1007/s00441-015-2224-6

Kowalczyk, T., Pontious, A., Englund, C., Daza, R. A. M., Bedogni, F., Hodge, R., et al. (2009). Intermediate neuronal progenitors (basal progenitors) produce pyramidal-projection neurons for all layers of cerebral cortex. Cereb. Cortex 19, 2439-2450. doi: 10.1093/cercor/bhn260

Kubo, K. I., Honda, T., Tomita, K., Sekine, K., Ishii, K., Uto, A., et al. (2010). Ectopic reelin induces neuronal aggregation with a normal birthdate-dependent "inside-out" alignment in the developing neocortex. J. Neurosci. 30, 1095310966. doi: 10.1523/JNEUROSCI.0486-10.2010

La Fata, G., Gärtner, A., Domínguez-Iturza, N., Dresselaers, T., Dawitz, J., Poorthuis, R. B., et al. (2014). FMRP regulates multipolar to bipolar transition affecting neuronal migration and cortical circuitry. Nat. Neurosci. 17, 16931700. doi: $10.1038 / \mathrm{nn} .3870$

Letinic, K., Zoncu, R., and Rakic, P. (2002). Origin of GABAergic neurons in the human neocortex. Nature 417, 645-649. doi: 10.1038/nature00779

Lim, L., Mi, D., Llorca, A., and Marín, O. (2018). Development and functional diversification of cortical interneurons. Neuron 100, 294-313. doi: 10.1016/j. neuron.2018.10.009

Liu, Z., Patel, K., Schmidt, H., Andrews, W., Pini, A., and Sundaresan, V. (2004). Extracellular Ig domains 1 and 2 of Robo are important for ligand (Slit) binding. Mol. Cell. Neurosci. 26, 232-240. doi: 10.1016/j.mcn.2004.01.002

Long, H., Sabatier, C., Ma, L., Plump, A., Yuan, W., Ornitz, D. M., et al. (2004). Conserved roles for Slit and Robo proteins in midline commissural axon guidance. Neuron 42, 213-223. doi: 10.1016/S0896-6273(04)00 $179-5$

López-Bendito, G., Flames, N., Ma, L., Fouquet, C., Di Meglio, T., Chedotal, A., et al. (2007). Robo1 and Robo2 cooperate to control the guidance of major axonal tracts in the mammalian forebrain. J. Neurosci. 27, 3395-3407. doi: 10.1523/JNEUROSCI.4605-06.2007

Lu, W., Van Eerde, A. M., Fan, X., Quintero-Rivera, F., Kulkarni, S., Ferguson, H., et al. (2007). Disruption of ROBO2 is associated with urinary tract anomalies and confers risk of vesicoureteral reflux. Am. J. Hum. Genet. 80, 616-632. doi: $10.1086 / 512735$

Lui, J. H., Hansen, D. V., and Kriegstein, A. R. (2011). Development and evolution of the human neocortex. Cell 146, 18-36. doi: 10.1016/j.cell.2011.06.030

Luzzati, F. (2015). A hypothesis for the evolution of the upper layers of the neocortex through co-option of the olfactory cortex developmental program. Front. Neurosci. 9:162. doi: 10.3389/fnins.2015.00162

Malatesta, P., Hartfuss, E., and Götz, M. (2000). Isolation of radial glial cells by fluorescent-activated cell sorting reveals a neural lineage. Development 127, 5253-5263.

Marillat, V., Cases, O., Nguyenf-Ba-Charvet, K. T., Tessier-Lavigne, M., Sotelo, C., and Chédotal, A. (2002). Spatiotemporal expression patterns of slit and robo genes in the rat brain. J. Comp. Neurol. 442, 130-155. doi: 10.1002/cne.10068
Marín, O., Plump, A. S., Flames, N., Sánchez-Camacho, C., Tessier-Lavigne, M., and Rubenstein, J. L. R. (2003). Directional guidance of interneuron migration to the cerebral cortex relies on subcortical Slit1/2-independent repulsion and cortical attraction. Development 130, 1889-1901. doi: 10.1242/dev.00417

Marín, O., Yaron, A., Bagri, A., Tessier-Lavigne, M., and Rubenstein, J. L. R. (2001). Sorting of striatal and cortical interneurons regulated by semaphorinneuropilin interactions. Science 293, 872-875. doi: 10.1126/science.1061891

Martynoga, B., Drechsel, D., and Guillemot, F. (2012). Molecular control of neurogenesis: a view from the mammalian cerebral cortex. Cold Spring Harb. Perspect. Biol. 4:a008359. doi: 10.1101/cshperspect.a008359

Mattar, P., Britz, O., Johannes, C., Nieto, M., Ma, L., Rebeyka, A., et al. (2004). A screen for downstream effectors of Neurogenin2 in the embryonic neocortex. Dev. Biol. 273, 373-389. doi: 10.1016/j.ydbio.2004.06.013

Mège, R. M., Gavard, J., and Lambert, M. (2006). Regulation of cell-cell junctions by the cytoskeleton. Curr. Opin. Cell Biol. 18, 541-548. doi: 10.1016/j.ceb.2006. 08.004

Miller, D. J., Bhaduri, A., Sestan, N., and Kriegstein, A. (2019). Shared and derived features of cellular diversity in the human cerebral cortex. Curr. Opin. Neurobiol. 56, 117-124. doi: 10.1016/j.conb.2018.12.005

Miyata, T., Kawaguchi, A., Okano, H., and Ogawa, M. (2001). Asymmetric inheritance of radial glial fibers by cortical neurons. Neuron $31,727-741$. doi: 10.1016/S0896-6273(01)00420-2

Mizutani, K. I., Yoon, K., Dang, L., Tokunaga, A., and Gaiano, N. (2007). Differential Notch signalling distinguishes neural stem cells from intermediate progenitors. Nature 449, 351-355. doi: 10.1038/nature06090

Moresco, E. M. Y., Donaldson, S., Williamson, A., and Koleske, A. J. (2005). Integrin-mediated dendrite branch maintenance requires Abelson (Abl) family kinases. J. Neurosci. 25, 6105-6118. doi: 10.1523/JNEUROSCI.1432-05.2005

Muller, C. L., Anacker, A. M. J., and Veenstra-VanderWeele, J. (2016). The serotonin system in autism spectrum disorder: from biomarker to animal models. Neuroscience 321, 24-41. doi: 10.1016/j.neuroscience.2015.11.010

Nadarajah, B., Brunstrom, J. E., Grutzendler, J., Wong, R. O. L., and Pearlman, A. L. (2001). Two modes of radial migration in early development of the cerebral cortex. Nat. Neurosci. 4, 143-150. doi: 10.1038/83967

Nagafuchi, A., and Takeichi, M. (1988). Cell binding function of E-cadherin is regulated by the cytoplasmic domain. EMBO J. 7, 3679-3684. doi: 10.1002/j. 1460-2075.1988.tb03249.x

Namba, T., Funahashi, Y., Nakamuta, S., Xu, C., Takano, T., and Kaibuchi, K. (2015). Extracellular and intracellular signaling for neuronal polarity. Physiol. Rev. 95, 995-1024. doi: 10.1152/physrev.00025.2014

Namba, T., and Huttner, W. B. (2017). Neural progenitor cells and their role in the development and evolutionary expansion of the neocortex. Wiley Interdiscip. Rev. Dev. Biol. 6:256. doi: 10.1002/wdev.256

Namba, T., Kibe, Y., Funahashi, Y., Nakamuta, S., Takano, T., Ueno, T., et al. (2014). Pioneering axons regulate neuronal polarization in the developing cerebral cortex. Neuron 81, 814-829. doi: 10.1016/j.neuron.2013.12.015

Noctor, S. C., Flint, A. C., Weissman, T. A., Dammerman, R. S., and Kriegstein, A. R. (2001). Neurons derived from radial glial cells establish radial units in neocortex. Nature 409, 714-720. doi: 10.1038/35055553

Nopola-Hemmi, J., Myllyluoma, B., Haltia, T., Taipale, M., Ollikainen, V., Ahonen, T., et al. (2001). A dominant gene for developmental dyslexia on chromosome 3. J. Med. Genet. 38, 658-664. doi: 10.1136/jmg.38.10.658

O'Dell, R. S., Cameron, D. A., Zipfel, W. R., and Olson, E. C. (2015). Reelin prevents apical neurite retraction during terminal translocation and dendrite initiation. J. Neurosci. 35, 10659-10674. doi: 10.1523/JNEUROSCI.1629-15.2015

O'Dell, R. S., Ustine, C. J. M., Cameron, D. A., Lawless, S. M., Williams, R. M., Zipfel, W. R., et al. (2012). Layer 6 cortical neurons require Reelin-Dab1 signaling for cellular orientation, Golgi deployment, and directed neurite growth into the marginal zone. Neural Dev. 7:25. doi: 10.1186/1749-8104-7-25

Ohata, S., Aoki, R., Kinoshita, S., Yamaguchi, M., Tsuruoka-Kinoshita, S., Tanaka, H., et al. (2011). Dual roles of notch in regulation of apically restricted mitosis and apicobasal polarity of neuroepithelial cells. Neuron 69, 215-230. doi: 10. 1016/j.neuron.2010.12.026

Ohtaka-Maruyama, C., and Okado, H. (2015). Molecular pathways underlying projection neuron production and migration during cerebral cortical development. Front. Neurosci. 9:447. doi: 10.3389/fnins.2015.00447

Ozawa, M., Baribault, H., and Kemler, R. (1989). The cytoplasmic domain of the cell adhesion molecule uvomorulin associates with three independent proteins 
structurally related in different species. EMBO J. 8, 1711-1717. doi: 10.1002/j. 1460-2075.1989.tb03563.x

Parcerisas, A., Pujadas, L., Ortega-Gascó, A., Perelló-Amorós, B., Viais, R., Hino, $\mathrm{K}$., et al. (2020). NCAM2 regulates dendritic and axonal differentiation through the cytoskeletal proteins MAP2 and 14-3-3. Cereb. Cortex 30, 3781-3799. doi: 10.1093/cercor/bhz342

Peterson, R. L., and Pennington, B. F. (2012). Developmental dyslexia. Lancet 379, 1997-2007. doi: 10.1016/S0140-6736(12)60198-6

Petros, T. J., Bultje, R. S., Ross, M. E., Fishell, G., and Anderson, S. A. (2015). Apical versus basal neurogenesis directs cortical interneuron subclass fate. Cell Rep. 13, 1090-1095. doi: 10.1016/j.celrep.2015.09.079

Pleasure, S. J., Anderson, S., Hevner, R., Bagri, A., Marin, O., Lowenstein, D. H., et al. (2000). Cell migration from the ganglionic eminences is required for the development of hippocampal GABAergic interneurons. Neuron 28, 727-740. doi: 10.1016/S0896-6273(00)00149-5

Poelmans, G., Buitelaar, J. K., Pauls, D. L., and Franke, B. (2011). A theoretical molecular network for dyslexia: integrating available genetic findings. Mol. Psychiatry 16, 365-382. doi: 10.1038/mp.2010.105

Polleux, F., Morrow, T., and Ghosh, A. (2000). Semaphorin 3A is a chemoattractant for cortical apical dendrites. Nature 404, 567-573. doi: 10.1038/35007001

Rakic, P. (1972). Mode of cell migration to the superficial layers of fetal monkey neocortex. J. Comp. Neurol. 145, 61-83. doi: 10.1002/cne.901450105

Rakic, P. (2009). Evolution of the neocortex: a perspective from developmental biology. Nat. Rev. Neurosci. 10, 724-735. doi: 10.1038/nrn2719

Reynolds, A. B., Daniel, J., McCrea, P. D., Wheelock, M. J., Wu, J., and Zhang, Z. (1994). Identification of a new catenin: the tyrosine kinase substrate p120cas associates with E-cadherin complexes. Mol. Cell. Biol. 14, 8333-8342. doi: 10. $1128 /$ mcb.14.12.8333

Rhee, J., Buchan, T., Zukerberg, L., Lilien, J., and Balsamo, J. (2007). Cables links Robo-bound Abl kinase to N-cadherin-bound $\beta$-catenin to mediate Slitinduced modulation of adhesion and transcription. Nat. Cell Biol. 9, 883-892. doi: $10.1038 /$ ncb1614

Rhee, J., Mahfooz, N. S., Arregui, C., Lilien, J., Balsamo, J., and VanBerkum, M. F. A. (2002). Activation of the repulsive receptor roundabout inhibits N-cadherinmediated cell adhesion. Nat. Cell Biol. 4, 798-805. doi: 10.1038/ncb858

Riccio, O., Jacobshagen, M., Golding, B., Vutskits, L., Jabaudon, D., Hornung, J. P., et al. (2011). Excess of serotonin affects neocortical pyramidal neuron migration. Transl. Psychiatry 1, 1-9. doi: 10.1038/tp.2011.49

Riccio, O., Potter, G., Walzer, C., Vallet, P., Szabó, G., Vutskits, L., et al. (2009). Excess of serotonin affects embryonic interneuron migration through activation of the serotonin receptor 6. Mol. Psychiatry 14, 280-290. doi: 10.1038/mp.2008. 89

Rincic, M., Rados, M., Krsnik, Z., Gotovac, K., Borovecki, F., Liehr, T., et al. (2016). Complex intrachromosomal rearrangement in $1 \mathrm{q}$ leading to $1 \mathrm{q} 32.2$ microdeletion: a potential role of $S R G A P 2$ in the gyrification of cerebral cortex. Mol. Cytogenet. 9, 1-11. doi: 10.1186/s13039-016-0221-4

Roberts, B. (2018). Neuronal migration disorders. Radiol. Technol. 89, 279-295. doi: 10.1007/978-3-540-35280-8_1715

Rothberg, J. M., Hartley, D. A., Walther, Z., and Artavanis-Tsakonas, S. (1988). Slit: an EGF-homologous locus of D. melanogaster involved in the development of the embryonic central nervous system. Cell 55, 1047-1059. doi: 10.1016/00928674(88)90249-8

Rothberg, J. M., Jacobs, J. R., Goodman, C. S., and Artavanis-Tsakonas, S. (1990). slit: an extracellular protein necessary for development of midline glia and commissural axon pathways contains both EGF and LRR domains. Genes Dev. 4, 2169-2187. doi: 10.1101/gad.4.12a.2169

Saitsu, H., Osaka, H., Sugiyama, S., Kurosawa, K., Mizuguchi, T., Nishiyama, K., et al. (2012). Early infantile epileptic encephalopathy associated with the disrupted gene encoding Slit-Robo Rho GTPase activating protein 2 (SRGAP2). Am. J. Med. Genet. Part A 158, 199-205. doi: 10.1002/ajmg.a.34363

Sasaki, T., Komatsu, Y., Watakabe, A., Sawada, K., and Yamamori, T. (2010). Prefrontal-enriched SLIT1 expression in old world monkey cortex established during the postnatal development. Cereb. Cortex 20, 2496-2510. doi: 10.1093/ cercor/bhp319

Schain, R. J., and Freedman, D. X. (1961). Studies on 5-hydroxyindole metabolism in autistic and other mentally retarded children. J. Pediatr. 58, 315-320. doi: $10.1016 / \mathrm{S} 0022-3476(61) 80261-8$
Schuurmans, C., Armant, O., Nieto, M., Stenman, J. M., Britz, O., Klenin, N., et al. (2004). Sequential phases of cortical specification involve neurogenindependent and -independent pathways. EMBO J. 23, 2892-2902. doi: 10.1038/ sj.emboj.7600278

Seeger, M., Tear, G., Ferres-Marco, D., and Goodman, C. S. (1993). Mutations affecting growth cone guidance in Drosophila: genes necessary for guidance toward or away from the midline. Neuron 10, 409-426. doi: 10.1016/08966273(93)90330-T

Sekine, K., Honda, T., Kawauchi, T., Kubo, K. I., and Nakajima, K. (2011). The outermost region of the developing cortical plate is crucial for both the switch of the radial migration mode and the dab1-dependent "inside-out" lamination in the neocortex. J. Neurosci. 31, 9426-9439. doi: 10.1523/JNEUROSCI.065011.2011

Sekine, K., Kawauchi, T., Kubo, K. I., Honda, T., Herz, J., Hattori, M., et al. (2012). Reelin controls neuronal positioning by promoting cell-matrix adhesion via inside-out activation of Integrin $\alpha 5 \beta 1$. Neuron 76, 353-369. doi: 10.1016/j. neuron.2012.07.020

Seong, E., Yuan, L., and Arikkath, J. (2015). Cadherins and catenins in dendrite and synapse morphogenesis. Cell Adhes. Migr. 9, 202-213. doi: 10.4161/19336918. 2014.994919

Silva, C. G., Peyre, E., and Nguyen, L. (2019). Cell migration promotes dynamic cellular interactions to control cerebral cortex morphogenesis. Nat. Rev. Neurosci. 20, 318-329. doi: 10.1038/s41583-019-0148-y

Soderling, S. H., Binns, K. L., Wayman, G. A., Davee, S. M., Ong, S. H., Pawson, T., et al. (2002). The WRP component of the WAVE-1 complex attenuates Rac-mediated signalling. Nat. Cell Biol. 4, 970-975. doi: 10.1038/ncb886

Soderling, S. H., Guire, E. S., Kaech, S., White, J., Zhang, F., Schutz, K., et al. (2007). A WAVE-1 and WRP signaling complex regulates spine density, synaptic plasticity, and memory. J. Neurosci. 27, 355-365. doi: 10.1523/JNEUROSCI. 3209-06.2006

Sporny, M., Guez-Haddad, J., Kreusch, A., Shakartzi, S., Neznansky, A., Cross, A., et al. (2017). Structural history of human SRGAP2 proteins. Mol. Biol. Evol. 34, 1463-1478. doi: 10.1093/molbev/msx094

Stein, C. M., Schick, J. H., Taylor, H. G., Shriberg, L. D., Millard, C., Kundtz-Kluge, A., et al. (2004). Pleiotropic effects of a chromosome 3 locus on speech-sound disorder and reading. Am. J. Hum. Genet. 74, 283-297. doi: 10.1086/381562

Sun, T., and Hevner, R. F. (2014). Growth and folding of the mammalian cerebral cortex: from molecules to malformations. Nat. Rev. Neurosci. 15, 217-232. doi: $10.1038 / \mathrm{nrn} 3707$

Sundaresan, V., Chung, G., Heppell-Parton, A., Xiong, J., Grundy, C., Roberts, I., et al. (1998a). Homozygous deletions at 3p12 in breast and lung cancer. Oncogene 17, 1723-1729. doi: 10.1038/sj.onc.1202103

Sundaresan, V., Roberts, I., Bateman, A., Bankier, A., Sheppard, M., Hobbs, C., et al. (1998b). The DUTT1 gene, a novel NCAM family member is expressed in developing murine neural tissues and has an unusually broad pattern of expression. Mol. Cell. Neurosci. 11, 29-35. doi: 10.1006/mcne.1998.0672

Tabata, H., and Nakajima, K. (2003). Multipolar migration: the third mode of radial neuronal migration in the developing cerebral cortex. J. Neurosci. 23, 9996-10001. doi: 10.1523/jneurosci.23-31-09996.2003

Tamamaki, N., Fujimori, K., Nojyo, Y., Kaneko, T., and Takauji, R. (2003). Evidence that Sema3A and Sema3F regulate the migration of GABAergic neurons in the developing neocortex. J. Comp. Neurol. 455, 238-248. doi: 10.1002/cne.10476

Tong, M., Jun, T., Nie, Y., Hao, J., and Fan, D. (2019). The role of the SLIT/Robo signaling pathway. J. Cancer 10, 2694-2705. doi: 10.7150/jca.31877

Tyler, W. A., Medalla, M., Guillamon-Vivancos, T., Luebke, J. I., and Haydar, T. F. (2015). Neural precursor lineages specify distinct neocortical pyramidal neuron types. J. Neurosci. 35, 6142-6152. doi: 10.1523/JNEUROSCI.0335-15.2015

Unni, D. K., Piper, M., Moldrich, R. X., Gobius, I., Liu, S., Fothergill, T., et al. (2012). Multiple Slits regulate the development of midline glial populations and the corpus callosum. Dev. Biol. 365, 36-49. doi: 10.1016/j.ydbio.2012.02.004

Varghese, M., Keshav, N., Jacot-Descombes, S., Warda, T., Wicinski, B., Dickstein, D. L., et al. (2017). Autism spectrum disorder: neuropathology and animal models. Acta Neuropathol. 134, 537-566. doi: 10.1007/s00401-017-1736-4

Vasistha, N. A., García-Moreno, F., Arora, S., Cheung, A. F. P., Arnold, S. J., Robertson, E. J., et al. (2015). Cortical and clonal contribution of Tbr2 expressing progenitors in the developing mouse brain. Cereb. Cortex 25, 32903302. doi: $10.1093 /$ cercor/bhu125 
Waltereit, R., Leimer, U., Von Bohlen Und Halbach, O., Panke, J., Hölter, S. M., Garrett, L., et al. (2012). Srgap3-/- mice present a neurodevelopmental disorder with schizophrenia-related intermediate phenotypes. FASEB J. 26, 4418-4428. doi: 10.1096/fj.11-202317

Wang, X., Tsai, J. W., Lamonica, B., and Kriegstein, A. R. (2011). A new subtype of progenitor cell in the mouse embryonic neocortex. Nat. Neurosci. 14, 555-562. doi: $10.1038 / \mathrm{nn} .2807$

Whitford, K. L., Marillat, V., Stein, E., Goodman, C. S., Tessier-Lavigne, M., Chédotal, A., et al. (2002). Regulation of cortical dendrite development by Slit-Robo interactions. Neuron 33, 47-61. doi: 10.1016/S0896-6273(01)0 0566-9

Wong, K., Ren, X. R., Huang, Y. Z., Xie, Y., Liu, G., Saito, H., et al. (2001). Signal transduction in neuronal migration: roles of GTPase activating proteins and the small GTPase Cdc42 in the Slit-Robo pathway. Cell 107, 209-221. doi: 10.1016/S0092-8674(01)00530-X

Yeh, M. L., Gonda, Y., Mommersteeg, M. T. M., Barber, M., Ypsilanti, A. R., Hanashima, C., et al. (2014). Robol modulates proliferation and neurogenesis in the developing neocortex. J. Neurosci. 34, 5717-5731. doi: 10.1523/ JNEUROSCI.4256-13.2014

Ypsilanti, A. R., Zagar, Y., and Chédotal, A. (2010). Moving away from the midline: New developments for Slit and Robo. Development 137, 1939-1952. doi: 10. 1242/dev.044511

Yuan, S. S. F., Cox, L. A., Dasika, G. K., and Lee, E. Y. H. P. (1999). Cloning and functional studies of a novel gene aberrantly expressed in RB-deficient embryos. Dev. Biol. 207, 62-75. doi: 10.1006/dbio.1998.9141
Yuan, W., Zhou, L., Chen, J. H., Wu, J. Y., Rao, Y., and Ornitz, D. M. (1999). The mouse SLIT family: secreted ligands for ROBO expressed in patterns that suggest a role in morphogenesis and axon guidance. Dev. Biol. 212, 290-306. doi: 10.1006/dbio.1999.9371

Zhang, B., Wang, W., Zhang, Z., Hu, Y., Meng, F., Wang, F., et al. (2018). Alternative splicing of disabled-1 controls multipolar-to-bipolar transition of migrating neurons in the neocortex. Cereb. Cortex 28, 3457-3467. doi: 10.1093/ cercor/bhx212

Zheng, W., Geng, A. Q., Li, P. F., Wang, Y., and Yuan, X. B. (2012). Robo4 regulates the radial migration of newborn neurons in developing neocortex. Cereb. Cortex 22, 2587-2601. doi: 10.1093/cercor/bhr330

Zhu, Y., Li, H. S., Zhou, L., Wu, J. Y., and Rao, Y. (1999). Cellular and molecular guidance of GABAergic neuronal migration from an extracortical origin to the neocortex. Neuron 23, 473-485. doi: 10.1016/S0896-6273(00)80801-6

Conflict of Interest: The authors declare that the research was conducted in the absence of any commercial or financial relationships that could be construed as a potential conflict of interest.

Copyright (c) 2020 Gonda, Namba and Hanashima. This is an open-access article distributed under the terms of the Creative Commons Attribution License (CC BY). The use, distribution or reproduction in other forums is permitted, provided the original author(s) and the copyright owner(s) are credited and that the original publication in this journal is cited, in accordance with accepted academic practice. No use, distribution or reproduction is permitted which does not comply with these terms. 